\title{
Analysis on Treatment Effect of Mine Tunnel Construction Spring in Karst Area
}

\author{
Bocheng Liu $\mathbb{D}^{1},{ }^{1}$ Wenlong Ye $\mathbb{D},{ }^{1}$ Chunming Zhu $\mathbb{D},{ }^{1}$ Ran Chen $\mathbb{D}^{2},{ }^{2}$ Songxian Huang $\mathbb{D},{ }^{2}$ \\ and Xiaodong $\mathrm{Ni} \mathbb{( i D}^{2}$ \\ ${ }^{1}$ Wuxi Metro Group Co., Ltd., Wuxi 210096, Jiangsu, China \\ ${ }^{2}$ Hohai University, Nanjing 210000, Jiangsu, China \\ Correspondence should be addressed to Xiaodong Ni; lulingnxd@126.com
}

Received 24 February 2021; Revised 18 March 2021; Accepted 22 March 2021; Published 5 April 2021

Academic Editor: Zhigang Tao

Copyright (C) 2021 Bocheng Liu et al. This is an open access article distributed under the Creative Commons Attribution License, which permits unrestricted use, distribution, and reproduction in any medium, provided the original work is properly cited.

The investigation of ultrashallow buried mining method in an interval revealed the existence of the karst fracture zone. The flow rate of 9 springs exposed in the initial excavation was relatively large, and the total water output per hour was nearly $300 \mathrm{~m}^{3}$. The filling materials in karst channels or fissures had the risk of bursting during excavation. Moreover, the ultrashallow buried tunnel undercrossed a special railway line, and the construction required higher surface deformation control. In view of the abovementioned risk problems, based on the grouting ideas of "assessment of influence," "determination of surrounding rock," "zone positioning," and "dynamic grouting," the grouting design scheme is dynamically optimized, and the grouting construction of surrounding water is cut off. Combined with the tunnel inspection, monitoring data, and numerical analysis, it is verified that the construction technology adopted in the project can ensure the stability of the project, which can provide a reference for similar projects.

\section{Introduction}

The existence of filling material in the karst channel or fissure makes tunnel excavation have great safety risk, and careless treatment may lead to karst collapse and surface settlement over limit. It is an urgent problem to dispose the karst area along the tunnel before construction to reduce the construction risk.

Grouting technology has been widely used in practical projects to reinforce tunnels [1] and porous rock [2].

The mechanism of grouting reinforcement of the surrounding rock is that the solidified slurry can block the water source and can increase the strength of the injected rock mass. That is, by influencing the microstructure, micropores can improve the macroscopic mechanical properties of rock. Finally, this technology can enhance the cohesion and internal friction angle of the structural surface [3]. Many previous studies on grouting theory have been conducted by scholars.
The exploitation and utilization of underground space have gradually become a hot spot of economic construction in China. At the same time, the karst area is widely distributed in China and has a strong disaster-causing nature. Bad geological disasters such as water inrush, mud inrush, and collapse are often encountered in the construction process of various underground projects.

The instability of the karst filling medium induced by the seepage-erosion process often causes serious water-mud inrush disasters, and the scientific evaluation of its grouting reinforcement effect of the karst filling medium is an important prerequisite for ensuring the safety of underground construction.

Relevant scholars [4-6] have carried out relevant studies on the mechanism of crack propagation in the rock mass, carried out corresponding numerical simulation analysis based on the research results, and achieved good results. The relevant results can provide an important reference for karst treatment. 
Many accidents during tunnel construction were reported in the past years, such as the Solan Tunnel, the Sanyang Tunnel, the Xiangshan Tunnel, the Yesanguan Tunnel, and the Maluqing Tunnel.

Chinese scholars have done a lot of research works on karst treatment technology and summarized a lot of mature work experience. In view of the karst problem encountered in the Maluqing Tunnel, which is known as the first of the eight risk tunnels on the whole Yiwan Railway, literature [7] puts forward the curtain grouting reinforcement and other engineering treatment technologies. According to the situation of a large semifilled karst cave in a mountain tunnel, a reasonable and scientific treatment method for karst cave was summarized in literature [8]. Literature studies $[9,10]$ combined with the karst problems encountered in the Nanning Metro Line 2 project studied the karst geometry and spatial characteristics, put forward the risk level of karst collapse, and accordingly formulated the corresponding karst treatment scheme. Domestic scholars have made many summaries on tunnel construction technology in karst areas in various regions [11-14]. Most of the research studies are focused on the highway or railway tunnels, and there are few introductions of karst treatment technology in the underground excavation section of the subway which requires strict deformation control of the surrounding environment. In particular, there are few research studies on the construction safety of ultrashallow buried tunnels under existing lines in karst areas and the influence of the surrounding environment. In this paper, a karst dynamic optimization grouting design scheme based on the control of water inrushing from microcracks is put forward according to the karst problem of an underground tunnel in a metro area. The rationality of the design scheme is verified by the comprehensive evaluation of the grouting reinforcement effect through inspection, monitoring data feedback, and numerical simulation.

\section{Engineering Profile}

In this karst area, the mine method tunnel passes through a special railway line. The buried depth of the tunnel is only $4.3 \mathrm{~m}$, and the deformation control value is $10 \mathrm{~mm}$ (the control value under dynamic load is $15 \mathrm{~mm}$ ). Therefore, the settlement control requirements are very high. The geophysical and pumping test data show that the right DK42 + 202 DK42 + 610 hole is located in the karst fracture zone with a total of $370 \mathrm{~m}$, with a large permeability coefficient of $1.62 \sim 1.75 \times 10^{-3} \mathrm{~cm} / \mathrm{s}$. A total of 9 significant water seepage points were revealed during the excavation of 50 meters in the karst belt. Figure 1 shows the schematic diagram of some water seepage points.

Water gushing pumping and drainage records show that the total water yield of 9 seepage points is about $250-300 \mathrm{~m}^{3}$ per hour, and the total amount of water seepage in 24 hours is up to $7000 \mathrm{~m}^{3}$, far greater than the normal construction displacement. The survey shows that the maximum water gushing point water pressure is approximately $0.38 \mathrm{MPa}$. The spout point has hidden danger to the subway construction, so it is necessary to take targeted prevention and control measures to eliminate the hidden danger according to the hydrogeological conditions and actual situation of the interval, so as to ensure that the tunnel passes through the existing track safely (entering the $158 \mathrm{~m}$ position in the karst area). At the same time, primary and secondary closed fissures develop in the bedrock of the karst broken zone. Under the influence of blasting, the original closed fissures may open to form water passage, resulting in large local water seepage and greater safety hidden danger. In actual engineering, it was found that 4 hours after blasting excavation, No. 3 leakage point appeared. With the progress of time, one day later, the water output was 5 times as original, and there was no decrease in leakage amount.

\section{Crack Propagation Mechanism under Water-Rock Coupling}

3.1. Mesocrack Propagation Mechanism. Under high hydraulic pressure, the fluid enters the crack, the hydrostatic pressure of the crack produces a normal expansion effect on the primary crack, and the hydrodynamic pressure of the crack produces a tangential force on the crack wall. Under the action of high dynamic and hydrostatic pressure, the stress state of the crack in the rock mass is changed, and the stress intensity factor at the crack tip is increased, which leads to the initiation, propagation, and connection of the crack in the rock mass. The hydraulic pressure of the crack intensifies the cracking, expansion, and connection of the crack in the rock mass and causes the progressive instability and failure of the rock mass. The interaction between seepage and fracture propagation of the fractured rock mass is the coupling effect of seepage and cracking in the fractured rock mass. In order to accurately simulate the crack propagation mechanism, a parallel bond stress corrosion model (PSC) with damage rate was used to simulate the aging characteristics of rock at the solid phase level based on the microparticle BPM model. The PSC model can show the formation, propagation, and coalescence of cracks intuitively. For the BPM model, rock weakening is essentially a process of gradual reduction of the parallel bond diameter between particles (see Figure 2), while the damage rate theory (see Figure 3) provides the rate of reduction of each parallel bond diameter. The main idea of the PSC model is to assume that stress corrosion only affects the cement, not the particles. The corrosion reaction only takes place on the bonded surface and the corrosion rate is proportional to the crack growth rate. In this way, we can consider the corrosion rate as the reduction rate of the parallel bond diameter and assume that the corrosion rate depends on the stress at the corrosion boundary and that stress corrosion will occur only when the tensile stress exceeds the subcritical crack threshold (stress threshold). The reduction rate of the parallel bond diameter between the confluence particles at the entrance can be expressed as

$$
\frac{\mathrm{d} \bar{D}}{\mathrm{~d} t}= \begin{cases}0, & \bar{\sigma}<\bar{\sigma}_{a}, \\ -\beta_{1} e^{\beta_{2}\left(\bar{\sigma} / \bar{\sigma}_{c}\right)}, & \bar{\sigma}_{a}<\bar{\sigma} \leq \bar{\sigma}_{c} \\ -\infty, & \bar{\sigma} \geq \bar{\sigma}_{c} .\end{cases}
$$

For this project, after selecting rock samples, the required transient mesomechanical parameters of rock are shown in Table 1, and the deformation curves of rock under 


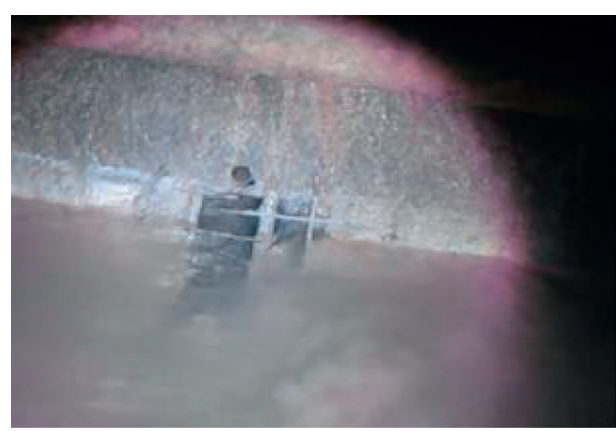

(a)

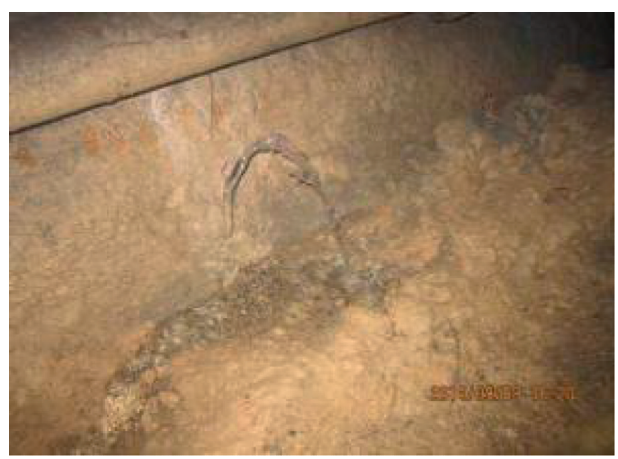

(c)

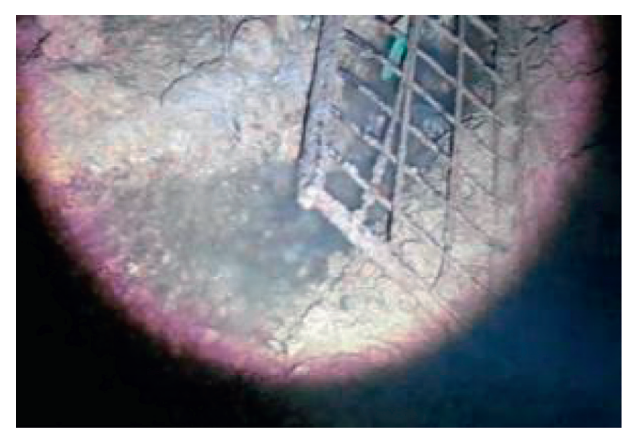

(b)

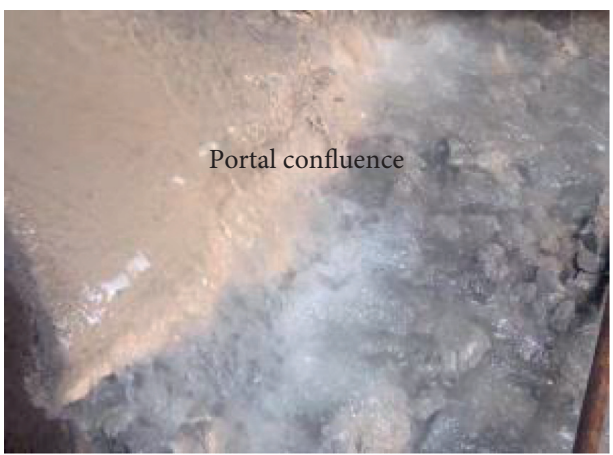

(d)

FIGURE 1: Schematic diagram of water seepage points in the interval.

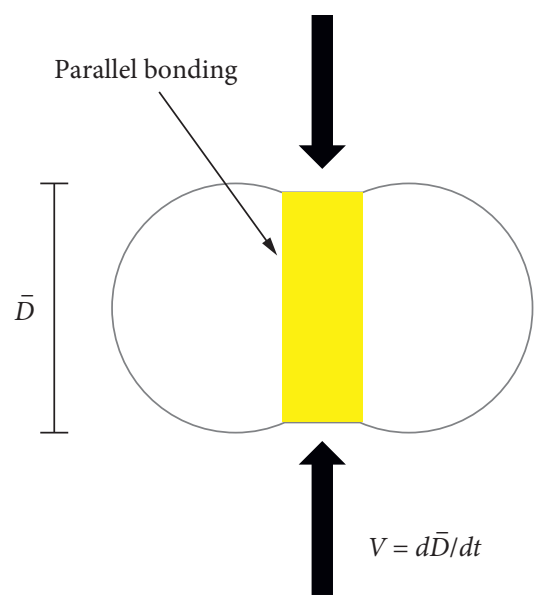

FIGURE 2: Reduction of the parallel bond diameter.

different stress states and stress paths can be obtained by loading PSC rheological model and aging mesomechanical parameters.

3.2. High-Speed Non-Darcy Flow through Fractures. From the perspective of engineering practicality, the Forchheimer equation is simple in form, few in parameters, and convenient in application. It can reflect the characteristics of Darcy flow and non-Darcy flow in porous media at the same time. Therefore, it is the most widely used formula for calculating seepage flow of non-Darcy flow in engineering at present.

$$
-\left.\frac{\mathrm{d} p}{\mathrm{~d} x}\right|_{\text {Forchheimer }}=\frac{\mu}{k} v+\rho \beta v^{2}
$$

In equation (2), the linear term represents the influence of viscous force, while the quadratic term represents the influence of inertial force. The research team studied the relationship between pressure gradient and various factors at different crack openings and roughness and obtained the relationship as follows [15]:

$$
\begin{aligned}
& -\nabla p=\frac{2.5+0.025(\mathrm{JRC}-1)}{b^{1.6}} V+\frac{0.042 \mathrm{JRC} \cdot \rho}{b}|V| \cdot V \mathrm{JRC} \leq 10, \\
& -\nabla p=\frac{4.6+0.075(\mathrm{JRC}-13)}{b^{1.8}} V+\frac{0.042 \mathrm{JRC} \cdot \rho}{b}|V| \cdot V \mathrm{JRC} \geq 12 .
\end{aligned}
$$

Based on the relationship shown in equation (3), the corresponding governing equation can be selected in the analysis model according to the crack opening, crack roughness, and water flow pattern.

3.3. Meso-Water-Rock Coupling Mechanism. At the mesoscopic level, the water-rock coupling is essentially a fluidrock interaction process. Figure 4 shows the schematic of coupling at the mesoscopic level, considering the stationary fluid-solid problem in the deformation configuration $\Omega=\Omega^{f}+\Omega^{s}$, where fluid occupies $\Omega^{f}$, solid occupies $\Omega^{s}$, and $\Omega^{f}$ studying $\Omega^{s}=\varnothing$. The shared boundary between fluid and solid is denoted by $\Gamma=\partial \Omega^{f} \cap \partial \Omega^{s}$ which will change during the crack growth process. Two conditions will occur on the interface. 


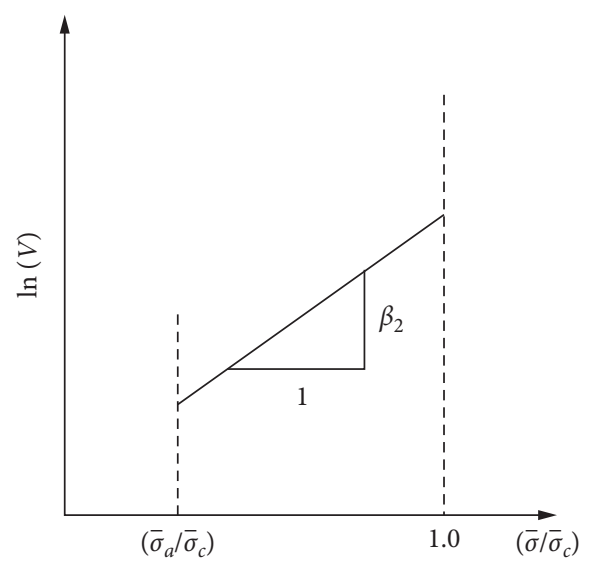

Figure 3: Damage rate.

TABle 1: Timing mesomechanical parameters of rock numerical model.

\begin{tabular}{lc}
\hline Rate constant $\beta_{1}(\mathrm{~m} / \mathrm{s})$ & $4 \times 10^{-10}$ \\
\hline Infinity compendium of constants $\beta_{2}$ & 10 \\
Microscopic activation stress $\bar{\sigma}_{a}(\mathrm{MPa})$ & 50 \\
\hline
\end{tabular}

Therefore, it is necessary to accurately solve the seepage field in the pores and fractures in order to obtain the distribution of static water pressure and velocity in the pores and fractures. Equation for mass conservation and equation for momentum conservation (N-S equation) are basic equations in the analysis of the seepage field in the pores and fractures. Assuming that the fluid is incompressible, the mass and momentum conservation equations are expressed as follows:

$$
\begin{aligned}
\frac{\partial \rho}{\partial t}+\nabla(\rho V) & =0, \\
\frac{\mathrm{d} V}{\mathrm{~d} t} & =F-\frac{1}{\rho} \nabla p+\nu \nabla^{2} V,
\end{aligned}
$$

where $V$ represents fluid velocity, $\rho$ represents fluid density, $F$ represents quality force, $p$ denotes pressure, and $v$ denotes kinematic viscous coefficient. According to the scheme, fluid pressure of the grid cell marked as $P_{i}$ is acting on the particle; the shear stress of $\tau_{i}$, which is caused by fluid flow around the particle had been introduced to the code of the program for analysis. The velocity distribution $u$ of Newtonian fluid for laminar flow in the domain $\Omega^{f}$ is assumed to be a function of $y$ only and is given by

$$
\tau_{f}=\mu \frac{d u}{d y}
$$

where $\mu$ represents the viscosity of the fluid and $y$ is assumed to be equal to the vertical distance from the node of the fluid grid to the surface of the particle.

Therefore, the total force acting on a particle is given by

$$
f_{c}=\sum_{i=1}^{m}\left(\mu \frac{d u_{i}}{d y_{i}} \frac{\pi d_{j}}{n}\right)
$$

where $i$ represents how many segments the boundary had been divided into, $m$ is the fraction number, and $d_{j}$ represents the diameter of the particle. Obviously, relying on the fine crack growth model in Section 3.1 and the distribution characteristics of the flow field in Section 3.2, combined with the coupling mechanism in Section 3.3, a fine study of the crack growth mechanism can be conducted. Based on this model, the hydraulic splitting samples in $[16,17]$ were simulated and analyzed. The simulation results were similar to the experimental results, indicating that the correlation separation method could reflect the mechanism of crack propagation. The model is shown in Figure 5.

\section{Control Scheme of Water Inrush from Microcracks}

4.1. Construction Steps and Methods of Grouting Treatment. The rock mass condition, the distribution of multiple water seepage points, and the large water yield revealed by the excavation of $50 \mathrm{~m}$ in the karst area indicate that there is a risk of seepage and surge in the tunnel, and the mining blasting construction may lead to further expansion of cracks in the karst area and aggravate the above risk. The underpass track is strictly controlled for deformation, so the construction safety risk is a level one. To reflect the situation in the actual project, a $3 \mathrm{~d}$ mesoscopic particles model had been built, and the crack extension under seepage force during excavation is shown in Figure 6.

According to the seepage volume in the actual engineering project, it can be deduced that the Reynolds number is up to 98, which is beyond the applicability of Darcy's law. Therefore, the effects of non-Darcian flow and the initiation and expansion of the crack of surrounding rock caused by water-rock coupling effect should be considered in the grouting design. Therefore, the research team put forward the karst dynamic optimization grouting design scheme based on microfissure water inrush control (control of microcrack inrush) disposal scheme.

Water inrush from microfractures is considered to be a key challenge in underground engineering. As shown in Figure 7 , on the basis of studying the microscale characteristics of the surrounding rock and local hydrogeological conditions, grouting is realized to control water inrush from microcracks, with the main purpose of strengthening the resistance of surrounding rock to seepage deformation and blocking the seepage channel of cracks. In view of the characteristics of geotechnical engineering revealed by the project, complete water plugging is realized by continuous grouting by reducing the distance between small holes. In addition, the grouting pressure adopts a gradient structure, and the shallow low pressure is convenient for grouting penetration. For the crack area far away from the perimeter of the cave as shown in Figure 8, the deep high-pressure grouting is used to achieve effective filling, as shown in Figure 7. Grouting ideas are based on "judgment surrounding rock," "zoning positioning," and "dynamic grouting." For specific implementation, according to the situation revealed by geophysical exploration and water seepage and fracture development at the hand surface, the 


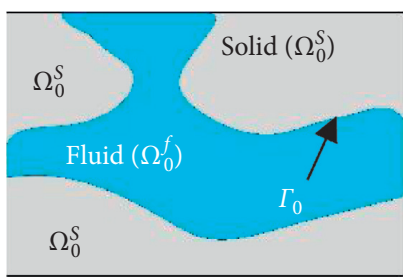

(a)

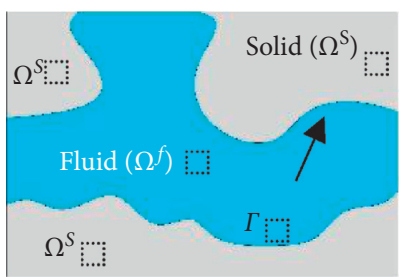

(b)

Figure 4: Schematic of fluid and structure domains. (a) Configuration at time T0. (b) Configuration at time T.

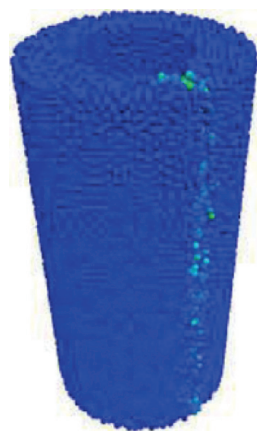

(a)

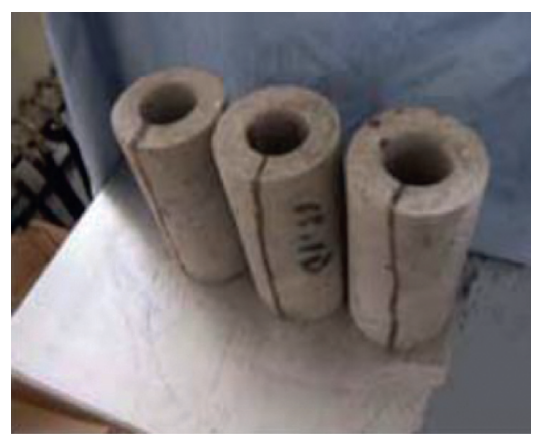

(b)

FIgURE 5: Fracture simulation of the model and failure diagram of the specimen in the literature.

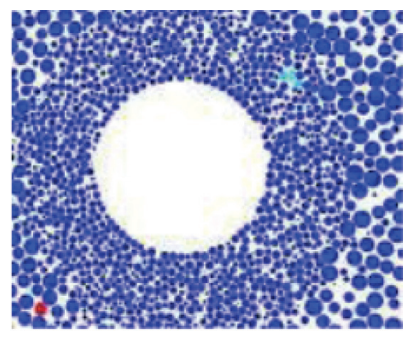

(a)

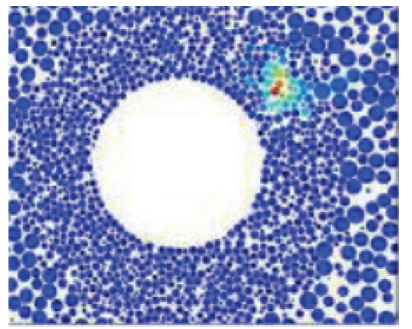

(c)

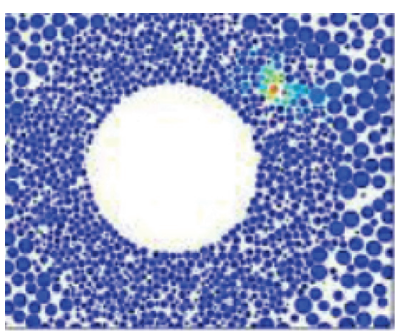

(b)

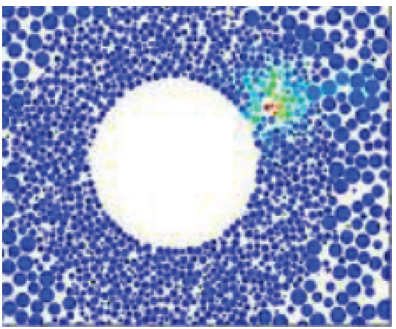

(d)

FIGURE 6: Schematic diagram of mesocrack propagation under permeability.

grouting area is divided into strong water area, general water area, and weak water area as shown in Figure 9. The water inrush control idea of microcracks is integrated to carry out dynamic grouting construction for strong water area, general water area, and weak water area, respectively.

According to the results of numerical analysis, the final scheme is as follows: a $2.0 \mathrm{~m} \times 2.0 \mathrm{~m}$ interval is used to drill holes in the weak water area within the radius of $3 \mathrm{~m}$ of the water seepage point. In the general area within the radius of $2 \mathrm{~m}$ of the main outlet hole, the spacing of holes is
$1.0 \mathrm{~m} \times 1.0 \mathrm{~m}$. Reinforce hole layout near the main water outlet or the main water flow channel, that is, drill holes within the radius of $1 \mathrm{~m}$ of the main water outlet with $0.5 \mathrm{~m} \times 0.5 \mathrm{~m}$ spacing, as shown in Figure 9. For grouting in different areas, the distance between holes, sequence grouting, grouting pressure, and other factors can be followed to achieve the control of water inrush from microcracks. In actual engineering, the maximum grouting pressure in the three areas extending outward from the perimeter of the tunnel is $0.18 \mathrm{MPa}, 0.34 \mathrm{MPa}$, and $0.47 \mathrm{MPa}$, respectively. 


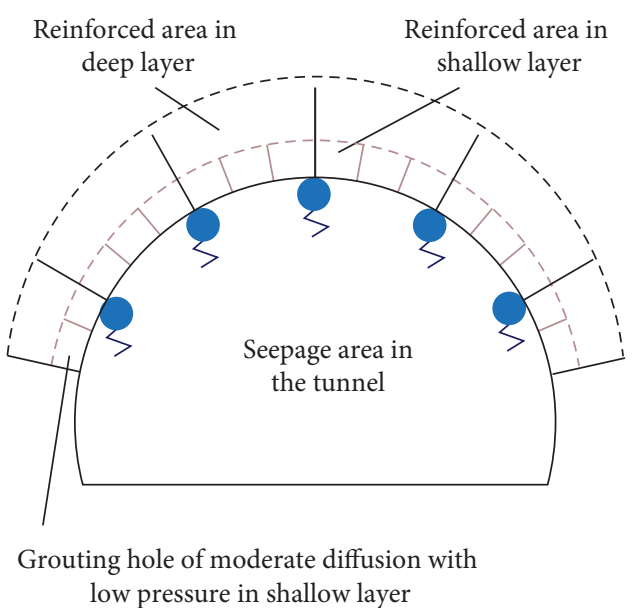

FIGURE 7: Schematic illustration of microcrack inrush control.

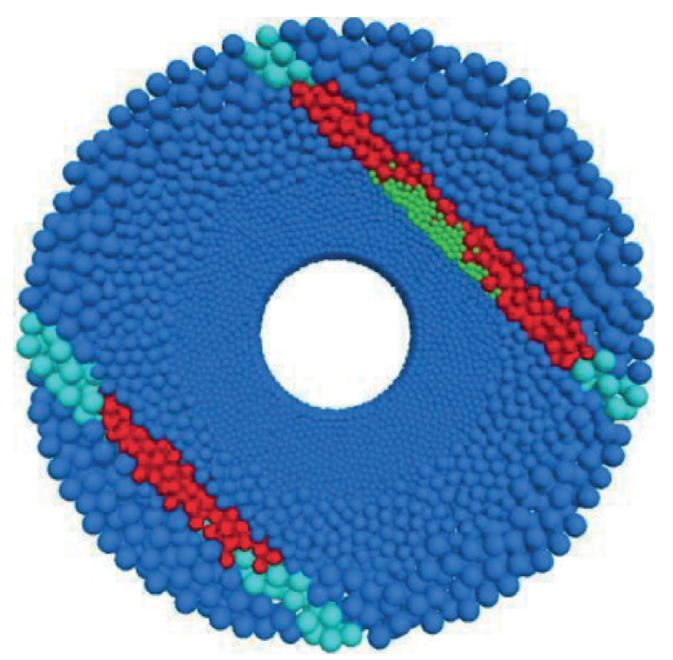

FIgURe 8: PFC3D model of tunnel fault.

Considering that the dynamic load of small freight train and the combined influence of excavation may lead to large surface subsidence in the key affected area under the special railway line and tunnel, the combined grouting in and out of the tunnel is adopted to strengthen the area.

\subsection{Difficulties Involved in Construction and Treatment} Methods. During site construction, different water seepage points should be treated comprehensively according to the water outlet of drilling holes. The principle of treatment is as follows: water diversion, decompression and precipitation, alternate plugging, and reinforcement.

The drilling is based on the orientation, width, inclination, space distribution of the crack, and the direction of the inrush current. Radial hole is used for reinforcement in the shallow layer, and key hole grouting is used for water plugging in the deep layer. Through multifactor optimization, well drilling evaluation and key well selection are realized. In addition, advanced information technology is used to accurately control the water-slurry ratio. The specific implementation is shown in Figure 10.
Related details in the grouting process are as follows:

(1) First inject without water hole, and then inject with water hole; the grouting sequence with water holes is from small water to concentrated water. To avoid the formation of a new outlet channel during the treatment of concentrated water, the hidden outlet channel in the tunnel section is fully filled by injecting no water hole. Fill a small amount of water first to avoid groundwater dispersion.

(2) In the treatments of gushing water, especially the number 3 gushing point, which water pressure is up to $3.8 \mathrm{MPa}$, first of all, oil-solubility polyurethane plugging agent was piped into main grouting pipe, as the agent's volume would expand rapidly and block the fissure after it reacts with water, and the gushing water quantity of the gushing point can be controlled temporarily. As cement slurry has a larger penetrating radius, and its durability is better than polyurethane plugging agent while polyurethane plugging agent is not durable enough and not environmentally friendly, it is not a good choice to grout too much polyurethane plugging agent. With the above reasons, circulation grouting of single grouting slurry and double grouting slurry was applied after the gushing water quantity of the gushing point had been controlled temporarily. This measurement can fill the crack of the surrounding rock behind initial support structure with grouting slurry mentioned above and finally block the seepage path completely.

(3) When plugging karst fissure water, the principle of gradual reinforcement should be followed. After water plugging and grouting with special grouting materials, grouting was carried out to reinforce the area by taking advantage of the large diffusion radius of pure cement grout to increase the effective reinforcement area. The effect of grouting disposal is shown in Figure 11.

\subsection{Numerical Model Analysis and Field Monitoring}

5.1. Numerical Model Establishment and Simulated Excavation. The relative positions of the tunnel and the railway subgrade are shown in Figure 12. The model is established based on the three-dimensional finite element analysis software ABAQUS. The lower boundary of the model is $3 \mathrm{D}$ from the bottom of the tunnel (tunnel $D=6.7 \mathrm{~m}$ ), the size of the model in the $Y$ direction is $32.3 \mathrm{~m}$, and the buried depth from the tunnel vault to the surface is $4.3 \mathrm{~m}$. The size of the model in the $X$ direction is $80 \mathrm{~m}$. Karst factor is taken into account when modeling, and silty clay is considered. The analysis parameters such as silty clay layer, moderately weathered limestone, and initial support are shown in Table 2. According to the core-taking test after grouting, the soil parameters after grouting are shown in Table 2. It can be estimated that the friction angle can be 


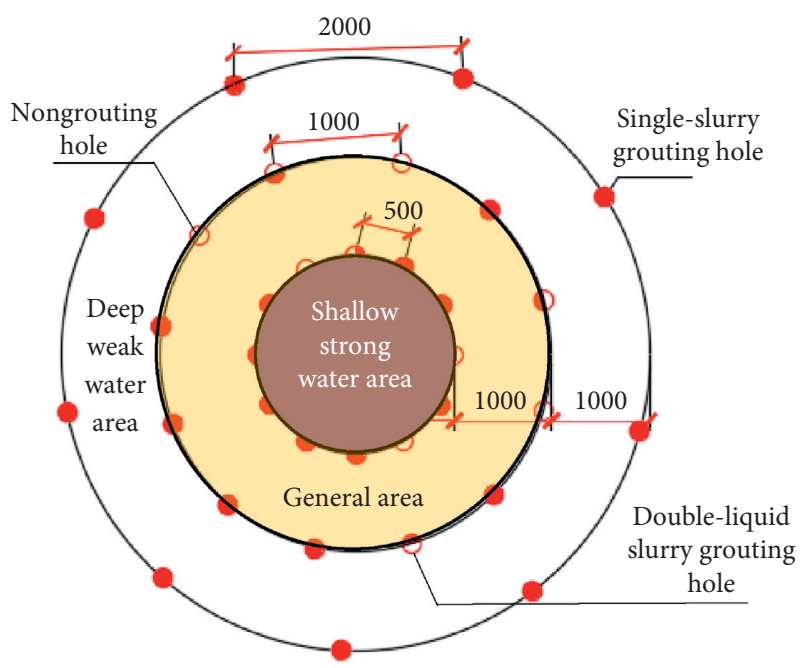

FIGURE 9: Grouting distribution diagram of the outlet water point.

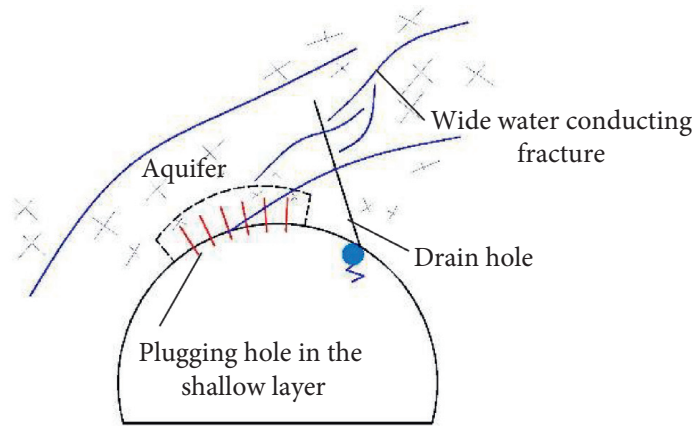

FIGURE 10: Schematic illustration of joint fissure water inrush control.

increased by $10^{\circ}$ and the cohesion can be increased by about $30 \%$ for the advanced support of pipe shed.

In the simulation of tunnel excavation and lining, considering the stress release process, the simulation was carried out according to the following scheme: (1) during the tunnel excavation, the stress release of surrounding rock was simulated by weakening the modulus of rock mass in the excavation area; (2) when the tunnel is excavated in class IV surrounding rock, the stress release ratio is set to $40 \%$, respectively (according to the relevant monitoring data and scientific research data); and (3) after the primary support is stabilized, secondary lining is considered to be applied. At this time, the deformation modulus of the surrounding rock in the excavation area is further reduced.

5.2. Numerical Analysis Results. Surface settlement is the key point of real-time monitoring and control in tunnel construction with the underground excavation method. In actual construction, monitoring points should be arranged along the tunnel axis defense line, and points on the top of rail should serve as both surface and track settlement points. In order to evaluate the effect of grouting, no grouting and no rail load during excavation (working condition 1), grouting but no rail load during excavation (working condition 2), grouting with rail load during during excavation (working condition 3) were simulated. The rationality of the grouting scheme is verified by comparing with the measured monitoring data.

5.2.1. Analysis Results of Working Condition 1. Firstly, the analysis results of different excavation stages under grouting condition without track load are given. Based on the left axis, Figure 13 shows the surface deformation curve without grouting.

As can be seen from the figure, the surface subsidence is significant after tunnel excavation. The settlement curve is consistent with the lateral distribution law of the Gaussian curve for the surface settlement caused by single-line tunnel construction, that is, the closer the distance to the central axis of the tunnel, the greater the settlement amount. The influence range of the settlement groove is within $\pm 25 \mathrm{~m}$ from the central line of the tunnel on the left line. During the first footage of excavation of the left line, the surface above the central line has settled $26.4 \mathrm{~mm}$. When the two lines are connected, the subsidence groove has a similar maximum value. Because the excavation is not carried out at the same time, the maximum surface subsidence above the left line is $36.5 \mathrm{~mm}$, and that above the right line is $36.6 \mathrm{~mm}$. 


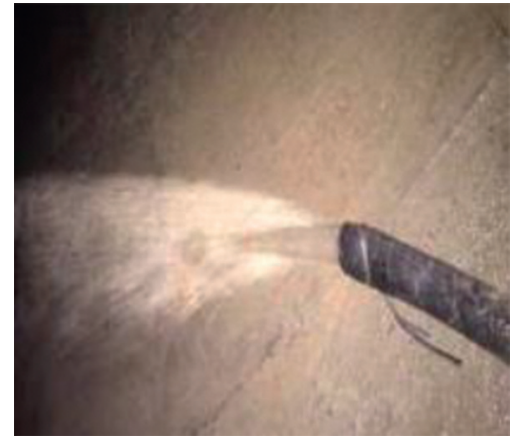

(a)

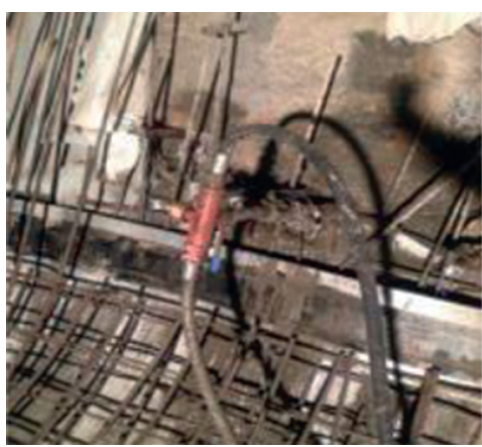

(b)

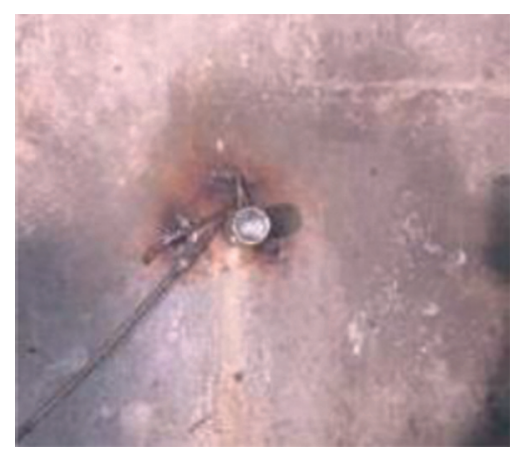

(c)

FIgURE 11: Effect drawing of grouting disposal.

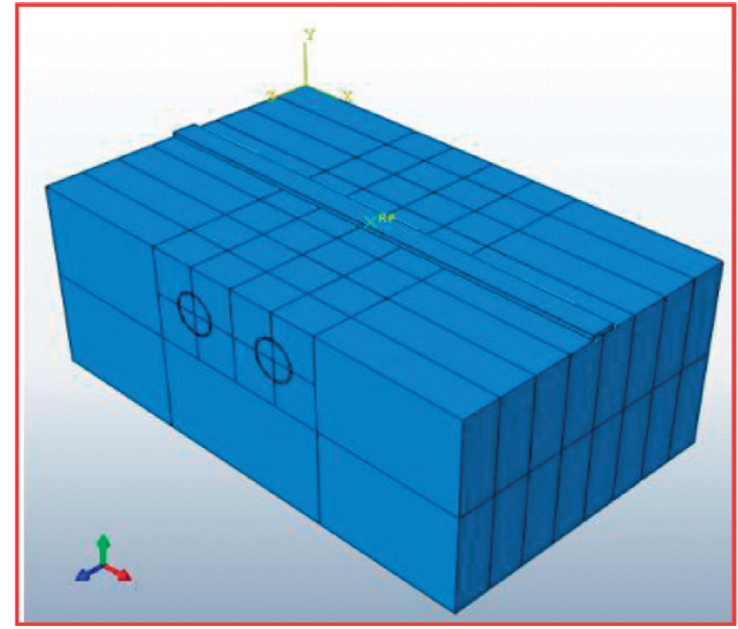

(a)

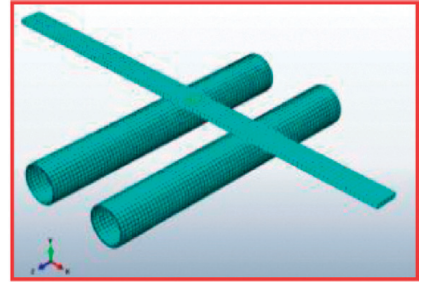

(b)

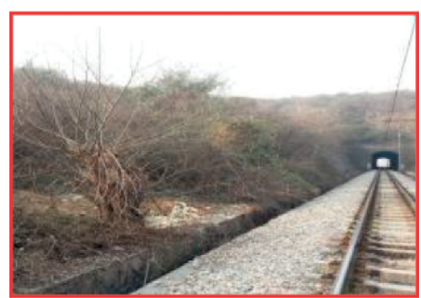

(c)

Figure 12: 3D models of existing tracks and interval tunnels.

TABle 2: Physical parameters of soil layer and lining.

\begin{tabular}{lcccccc}
\hline Soil layer and support & $\begin{array}{c}\text { Bulk density } \\
\left(\mathrm{kN} \cdot \mathrm{m}^{3}\right)\end{array}$ & $\begin{array}{c}\text { Poisson's } \\
\text { ratio }\end{array}$ & $\begin{array}{c}\text { Elastic modulus } \\
(\mathrm{MPa})\end{array}$ & $\begin{array}{c}\text { Cohesive force } \\
(\mathrm{kPa})\end{array}$ & $\begin{array}{c}\text { Friction angle } \\
\left({ }^{\circ}\right)\end{array}$ & $\begin{array}{c}\text { Thickness } \\
(\mathrm{m})\end{array}$ \\
\hline Silty clay & 19.3 & 0.35 & 22.59 & 46 & 24.4 & 15.6 \\
Weathered limestone & 25.5 & 0.26 & 40200 & 670 & 40 & 16.7 \\
Shallow strong water & 21.3 & 0.31 & 200.3 & 130 & 28.9 & 1.0 \\
area & 20.9 & 0.31 & 182.8 & 125 & 28.1 \\
General area & 20.5 & 0.33 & 170.2 & 118 & 26.7 & 1.0 \\
Deep weak water area & 25 & 0.2 & 25000 & - & - & 0.3 \\
Initial support & & & & & \\
\end{tabular}

5.2.2. Analysis Results of Working Condition 2. The karst in the existing track area is penetrated by combined grouting treatment on the surface and inside the cave, and the grouting scheme is as described above. As can be seen from Figure 14, the grouting reinforcement has a significant control effect on the surface settlement, and the affected area of the settlement groove is shrunk to $\pm 15 \mathrm{~m}$ from the middle line of the tunnel. After penetration, the surface subsidence decreased from $36.6 \mathrm{~mm}$ to $6.6 \mathrm{~mm}$, about $1 / 6$, indicating that the grouting played a positive role in controlling the surface deformation caused by excavation.

5.2.3. Analysis Results of Working Condition 3. In order to consider the surface grouting reinforcement and reinforcement in the tunnel (No. 3 seepage point), for the subgrade settlement under reciprocating load, consider the dynamic load transmitted by the wheel load to the subgrade 


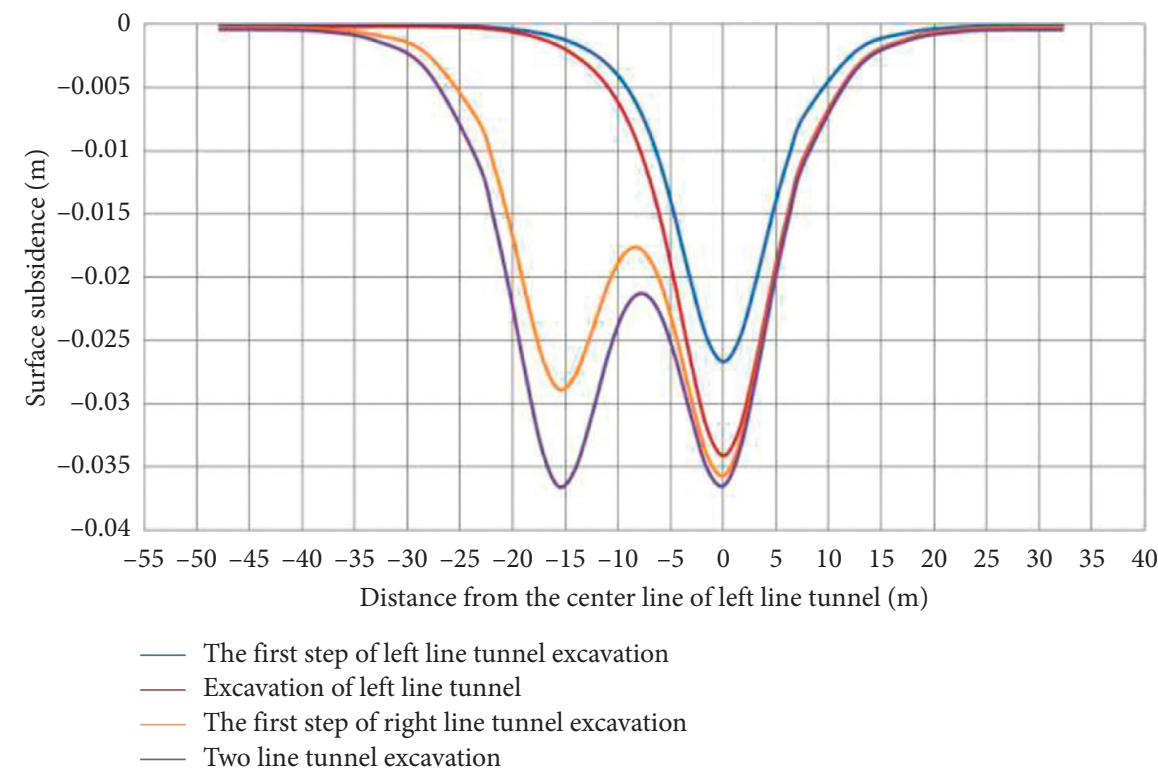

FIgURE 13: Surface settlement distribution curve.

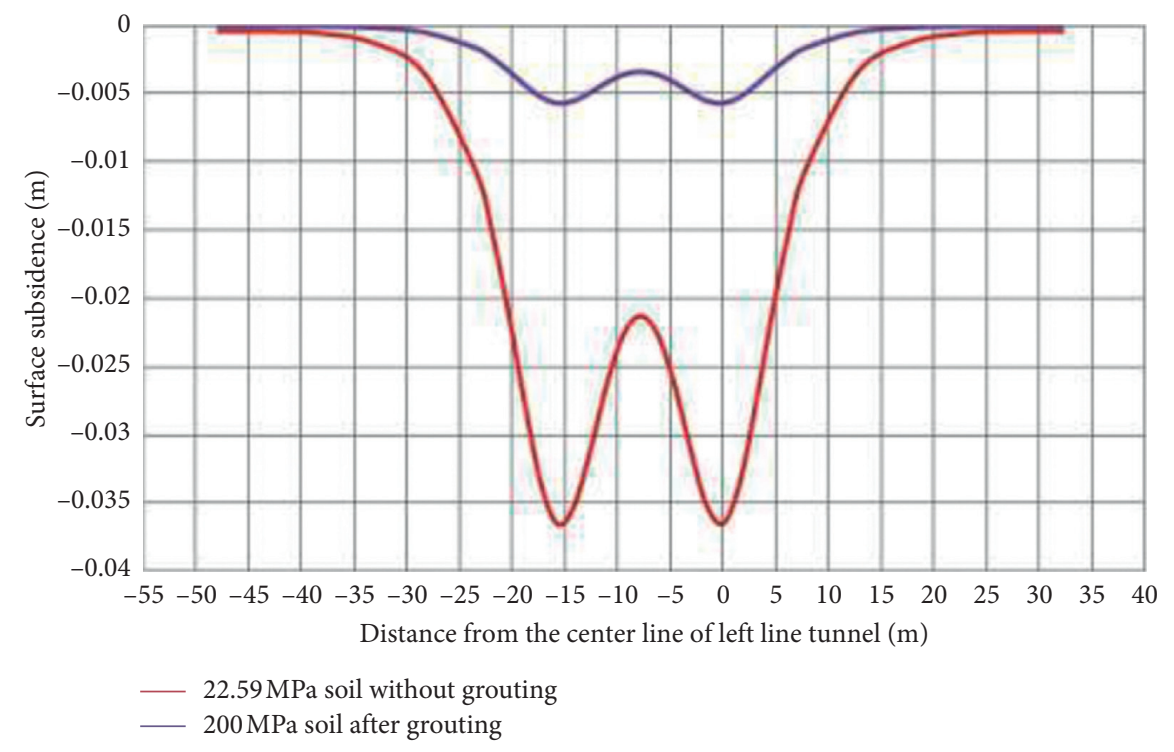

FIGURE 14: Surface settlement curve of two-line tunnel excavated after reinforcement.

surface through the superstructure when the vehicle is running. The biased sinusoidal wave is simplified. The final equivalent load is applied in the form of uniform load. The influence of the train operation below $120 \mathrm{~km} / \mathrm{h}$ on the surface settlement is mainly considered. $P=24.8 \mathrm{kN} / \mathrm{m}^{2}$ is taken according to the relevant data and the actual situation of the project. When the subgrade load is taken into account, the surface deformation presents an obvious settlement groove, and the settlement is the largest at the center line of the subgrade load, and the maximum settlement is $13 \mathrm{~mm}$ when both lines are excavated. When the subgrade load is not taken into account, the maximum surface settlement above the entrance is $6.60 \mathrm{~mm}$, and the surface deformation curve is basically straight after the excavation passes through the subgrade $15 \mathrm{~m}$, and there is no significant increase or decrease in the surface settlement. 


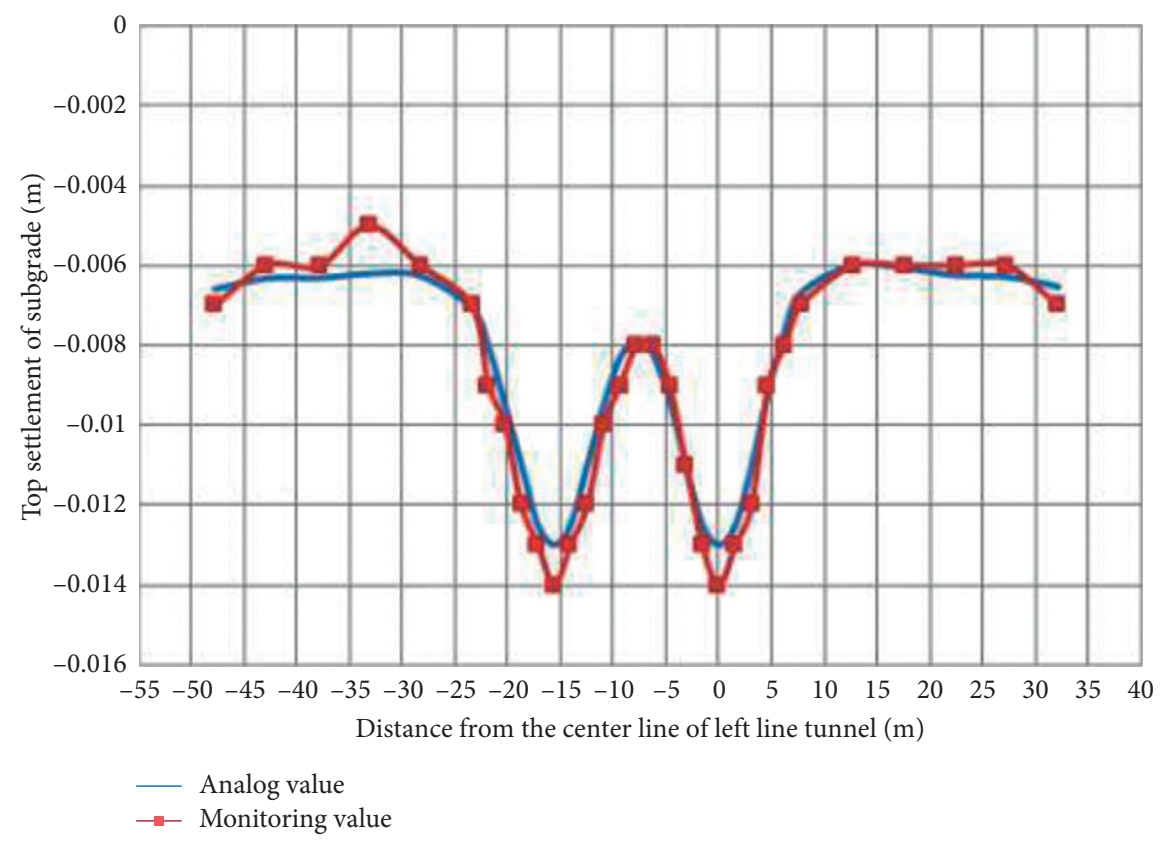

FIgURE 15: Monitoring point values and simulation information of track subgrade settlement.

Figure 15 shows that the monitoring results are close to the numerical simulation results, and the differences may come from the heterogeneity of the soil layer itself or the uneven grouting effect of the soil layer. In addition, the subgrade monitoring data are relatively stable values obtained after a period of operation, which are somewhat different from the actual situation.

\section{Conclusion}

(1) The coupling mechanism of seepage stress in fractured rock mass in the karst area was studied, and the microcrack propagation mechanism was analyzed in combination with non-Darcy seepage state, and the grouting optimization scheme based on water inrush control of microcracks was put forward.

(2) Based on the "assessment of impact," "determination of surrounding rock," "zoning positioning," "dynamic grouting," and combined with the optimization scheme based on microcrack water inrush control, in the actual project, it is found that the hole in the spring and the surrounding geological cracks are fully filled, and the downstream water output is greatly reduced, which achieves the expected effect and provides a reliable guarantee for the subsequent construction of the secondary lining. Later, inspection of the tunnel without obvious moisture and leakage shows that the plugging effect is good.

(3) In view of the characteristics of strict deformation control and high risk of water inrush in the karst fracture area of the tunnel under the existing track, the water inrush control scheme based on microcracks proposed in this paper is of great engineering value in order to realize the microdisturbance control of construction deformation in the key position of karst fracture area.

\section{Data Availability}

The data used to support the findings of this study are available from the corresponding author upon request.

\section{Conflicts of Interest}

The authors declare that they have no conflicts of interest.

\section{Acknowledgments}

The authors would like to acknowledge the financial support provided by the Fundamental Research Funds for the Central Universities (B200202077), the State Key Program of National Natural Science of China (201841830110), the National Natural Science Foundation of China (51779083), and the Major State Basic Research Development Program (2017YFC1502602).

\section{References}

[1] Å. Fransson, C.-F. Tsang, J. Rutqvist, and G. Gustafson, "Estimation of deformation and stiffness of fractures close to tunnels using data from single-hole hydraulic testing and grouting," International Journal of Rock Mechanics and Mining Sciences, vol. 47, no. 6, pp. 887893, 2010.

[2] Q. Wang, Q. Qin, B. Jiang et al., "Mechanized construction of fabricated arches for large-diameter tunnels," Automation in Construction.vol. 124, Article ID 103583, 2021. 
[3] R. Gothäll and H. Stille, "Fracture-fracture interaction during grouting," Tunneling and Underground Space Technology, vol. 25, no. 3, pp. 199-204, 2010.

[4] Y. Wang, B. Zhang, S. H. Gao, and C. H. Li, "Investigation on the effect of freeze-thaw on fracture mode classification in marble subjected to multi-level cyclic loads," Theoretical and Applied Fracture Mechanics, vol. 111, Article ID 102847, 2021.

[5] J. F. Chen, Y. F. Huang, and F. Z. Xiong, "Analysis of microcrack expansion during confined water rise," Geology and Exploration, vol. 53, no. 1, pp. 157-163, 2017.

[6] W. Liu, J. Zhao, R. Nie, Y. Zeng, B. Xu, and Xi Sun, "A full coupled thermal-hydraulic-chemical model for heterogeneity rock damage and its application in predicting water inrush," Applied Sciences, vol. 11, no. 9, 2019.

[7] Q. Wang, H. Gao, B. Jiang, S. Li, M. He, and Q. Qin, "In-situ test and bolt-grouting design evaluation method of underground engineering based on digital drilling," International Journal of Rock Mechanics and Mining Sciences, vol. 138, Article ID 104575, 2021.

[8] H. Huang, T. Babadagli, X. Chen, H. Li, and Y. Zhang, "Performance comparison of novel chemical agents for mitigating water-blocking problem in tight gas sandstones," SPE Reservoir Evaluation \& Engineering, vol. 23, no. 4, pp. 1150-1158, 2020.

[9] X. D. Ou, B. X. Luo, J. Jiang, S. Li, and Y. H. Zhong, "Analysis of karst treatment scheme in shield tunnel of nanning subway line 2," Construction Technology, vol. 47, no. 21, pp. 36-41, 2018.

[10] G. F. He, X. Q. Luo, X. Y. Fan, Y. Zhang, and H. Zhang, "Risk analysis and principle of management of karst in nanning metro line 2," Railway Standard Design, vol. 62, no. 5, pp. 86-90, 2018.

[11] J. F. Yi, S. B. Lu, J. Y. Rao, and T. Xie, "Safety construction technology for the muti-cavern tunnel of guiyang subway," Construction Technology, vol. 45, no. 13, pp. 101-104, 2016.

[12] Q.-X. Meng, W.-Y. Xu, H.-L. Wang, X.-Y. Zhuang, W.-C. Xie, and T. Rabczuk, "DigiSim-an open source software package for heterogeneous material modeling based on digital image processing," Advances in Engineering Software, vol. 148, Article ID 102836, 2020.

[13] Z. Tao, C. Zhu, M. He, and M. Karakus, "A physical modeling-based study on the control mechanisms of Negative Poisson's ratio anchor cable on the stratified toppling deformation of anti-inclined slopes," International Journal of Rock Mechanics and Mining Sciences, vol. 138, Article ID 104632, 2021.

[14] B. Li, R. Bao, Y. Wang, R. Liu, and C. Zhao, "Permeability evolution of two-dimensional fracture networks during shear under constant normal stiffness boundary conditions," Rock Mechanics and Rock Engineering, vol. 54, no. 3, pp. 1-20, 2021.

[15] X. Ni, Y. Niu, Y. Wang, and Y. Ke, "Non-Darcy flow experiments of water seepage through rough-walled rock fractures," Geoflfluids, vol. 2018, Article ID 8541421, 12 pages, 2018.

[16] M. Zhan and C. E. N. Jian, "Experimental and analytical study on hydraulic fracturing of cylinder sample," Chinese Journal of Rock Mechanics and Engineering, vol. 26, no. 6, pp. 1173-1181, 2007.

[17] J. Yu, W. Yao, K. Duan, X. Liu, and Y. Zhu, "Experimental study and discrete element method modeling of compression and permeability behaviors of weakly anisotropic sandstones," International Journal of Rock Mechanics and Mining Sciences, vol. 134, Article ID 104437, 2020. 